\title{
Avaliação ultra-sonográfica e pelo Doppler colorido do carcinoma de células transicionais da bexiga em cães
}

[Ultrasonography and color Doppler investigation of transicional cell carcinoma of the bladder in dogs]

\author{
T.R. Froes ${ }^{1}$, M. Iwasaki ${ }^{2}$, A.G. Campos $^{3}$, L.N. Torres $^{3}$, M.L.Z. Dagli ${ }^{2}$ \\ ${ }^{1}$ Departamento de Medicina Veterinária - UFPR \\ Rua dos Funcionários, 150 - Campus Juvevê \\ 80035-050 - Curitiba, PR \\ ${ }^{2}$ Faculdade de Medicina Veterinária e Zootecnia - USP - São Paulo, SP \\ ${ }^{3}$ Hospital Veterinário - FMVZ-USP - São Paulo, SP
}

\begin{abstract}
RESUMO
Estudaram-se os aspectos ultra-sonográficos das lesões sugestivas de carcinoma de células transicionais (CCT), investigou-se a contribuição do mapeamento Doppler colorido e de amplitude no diagnóstico das lesões sugestivas de CCT e verificou-se a acurácia do método de biópsia ecodirigida por sucção traumática via sondagem uretral na coleta de material para confirmação diagnóstica CCT da bexiga. Para tal, foram selecionados nove cães que atendiam aos critérios de inclusão determinados. Destes, sete apresentavam CCT. A ultra-sonografia permitiu a detecção de massas exofílicas com características vegetantes em cinco cães, e de lesões infiltrativas na parede vesical estendendo-se para a uretra em dois. Pelo exame com Doppler colorido e de amplitude, constatou-se a vascularização interna da massa, indicativa de neoangiogênese tumoral, em quatro animais. A técnica de sucção traumática por aspiração permitiu a elucidação diagnóstica em cinco dos sete animais com CCT. Concluiu-se que, na maioria dos casos, a ultra-sonografia propicia a identificação de lesões sugestivas de CCT, constituindo a primeira técnica de diagnóstico por imagem indicada para pacientes que apresentem hematúria e disúria.
\end{abstract}

Palavras-chave: cão, bexiga, ultra-sonografia, Doppler, carcinoma de células transicionais

\begin{abstract}
The aims of this study were to evaluate the ultrasonographic findings in dogs with suggestive transitional cell carcinoma (TCC) lesion, to investigate the use of the color Doppler for the diagnosis of that condition and to establish the efficacy of the ultrasound catheter biopsy by suction via urethral probing for collecting material to confirm bladder TCC. A total of nine dogs were selected, seven with TCC confirmed. The ultrasonographic finding in TCC patients detected sessile masses in the bladder of five dogs and infiltrative mural lesion extent to the urethra in two dogs. The color Doppler and the power Doppler showed the internal vascular flow in four animals indicating tumor neoangiogenesis. It was concluded that the ultrasonography may identify abnormalities in the majority of cases with suggestive lesions of TCC and the ultrasonographic evaluation should be considered as the first diagnostic imaging modality in patients presented with hematuria and dysuria.
\end{abstract}

Keywords: dog, bladder, ultrasound, doppler, transitional cell carcinoma

Recebido em 29 de março de 2006

Aceito em 13 de setembro de 2007

E-mail: tilde@ufp.br

Apoio: FAPESP 


\section{INTRODUÇÃO}

Dentre todos os tumores que acometem os cães, as neoplasias da bexiga respondem por apenas 0,5 e $1 \%$ dos casos, conforme Henry (2003). A extensa revisão de literatura realizada por esse pesquisador levou-o a concluir que o carcinoma de células transicionais (CCT) é o tipo histológico tumoral mais comumente encontrado no trato urinário de cães, representando de 50 a $75 \%$ das neoplasias malignas da bexiga.

A etiologia dos CCT em cães é considerada multifatorial. Os fatores de risco identificados incluem obesidade e exposição a produtos tóxicos, pulicidas e carrapaticidas. Aparentemente, há predisposição racial, pois Sheepdogs, Beagles, Collies e Terriers apresentam maior prevalência, e sexual, já que as fêmeas entre nove e 11 anos são as mais acometidas. Embora com menor freqüência, alguns pesquisadores citam que animais jovens também podem ser acometidos (Caywood et al., 2003; Henry, 2003).

Os sinais clínicos observados estão associados a doenças do trato urinário e compreendem polaquiúria, estrangúria, hematúria ou tenesmos. Relatos constantes da literatura apontam históricos de melhora clínica em resposta à antibioticoterapia em animais acometidos pelo CCT (Phillips, 1999).

Com relação aos métodos diagnósticos, sabe-se que células neoplásicas epiteliais podem ser identificadas na urinálise, sedimentoscopia, em $30 \%$ dos casos de CCT, mas a principal dificuldade reside na distinção entre essas células e as epiteliais transicionais reativas. Habitualmente, os achados hematológicos e bioquímicos estão dentro dos padrões de normalidade, a menos que a obstrução urinária tenha resultado em azotemia (Henry, 2003).

Atualmente, existe um teste de aglutinação rápida que utiliza antígenos de tumor vesical para a rápida detecção do CCT. Esse produto, disponível nos Estados Unidos da América, é denominado $V$-BTA test. Estudos comprovam a alta sensibilidade desse teste em casos de CCT, mas apontam que a sua especificidade é moderada (Henry et al., 2003).
Durante muitos anos, a uretrocistografia retrógrada positiva de duplo contraste e a urografia excretora foram rotineiramente indicadas como os procedimentos de imagem mais indicados no diagnóstico das vias urinárias caudais, principalmente quando da suspeita de CCT. Entretanto, quando comparados à ultrasonografia, tais métodos demonstram consumir mais tempo, ser relativamente mais invasivos e dissipar radiação ionizante (Léveillé et al., 1992; Park e Wrigley, 2003).

A ultra-sonografia é o método de diagnóstico por imagem, atualmente, utilizado na identificação de alterações sugestivas de processo neoplásico em animais com sinais clínicos de hematúria, disúria, polaquiúria e cistites infecciosas recorrentes. A cisto-sonografia permite uma boa avaliação do conteúdo luminal e da parede da bexiga urinária (Léveillé et al., 1992; Park e Wrigley, 2003).

A maioria das lesões está restrita à mucosa e à submucosa, e a invasão dos ureteres e da uretra é comum quando o tumor se origina próximo dessas estruturas. No homem, sabe-se que a disseminação linfática do tumor ocorre geralmente para a cadeia ilíaca externa. Os sítios mais comuns de metástases são o fígado, os pulmões e o esqueleto (Gianini e Cerri, 2002).

As características sonográficas visualizadas nos casos de tumores exofíticos são massas focais ou multifocais, hiperecogênicas ou de ecogenicidade mista, normalmente com contorno irregular e vegetante, projetando-se a partir da superfície interna da parede vesical e protraindose para o lúmen. Tais massas podem apresentar ecogenicidade sugestiva de áreas de fibrose, mineralização e necrose em seu interior (Nyland et al., 2002; Park e Wrigley, 2003). Habitualmente, essa alteração da parede vesical é localizada na região de trígono, embora em alguns casos possa estar presente na parede vesical dorsal ou mesmo ventral. A detecção de alteração na região ventral da parede da bexiga foi descrita em um dos 14 animais com CCT avaliados sonograficamente por Léveillé et al. (1992).

Investigadores ressaltam que a transição abrupta da região normal da parede em relação à região da massa é uma característica sonográfica que normalmente ocorre nos casos de CCT. 
Pesquisas revelam que a acurácia da ultrasonografia na detecção de tumores vesicais depende do tamanho do tumor, da sua localização e ainda da característica física do paciente no que se refere à obesidade (FinnBodner, 1995). Na medicina veterinária, acredita-se que massas maiores que $3 \mathrm{~mm}$ de diâmetro possam ser identificadas (Léveillé et al., 1992).

Tumores infiltrativos ocasionalmente mostram pequeno componente intraluminal e espessamento irregular e infiltrativo da parede localizado, via de regra, na região de trígono, aspecto também caracterizado como achado sonográfico sugestivo de CCT (Léveillé et al., 1992; Finn-Bodner, 1995).

Quando as alterações sonográficas geram a suspeição de CCT, toda a cavidade abdominal deve ser minuciosamente avaliada à procura de outras alterações, quer sejam elas relacionadas a processos obstrutivos, como hidronefrose e/ou megaureter, quer sejam sugestivas de metástases, quando são constatadas linfonodomegalias sublombares (ilíacas). Além dessas vantagens, sabe-se que a ultra-sonografia abdominal é importante na coleta de material para biópsias (Park e Wrigley, 2003).

O diagnóstico definitivo do CCT deve ser fundamentado em procedimentos diagnósticos por imagem que demonstrem a presença de massa na bexiga, associados à citologia, de preferência à histologia, que confirme a presença de células neoplásicas (Lamb et al., 1996; Henry, 2003).

Quanto à colheita de material para análise, a literatura apresenta diferentes formas, como a biópsia ecodirigida por meio de caracterização uretral, a cistoscopia ou a laparotomia (Lamb et al., 1996; Phillips, 1999; Henry, 2003).

As técnicas Doppler colorido e Doppler de amplitude têm sido sugeridas para auxiliar na determinação do $\mathrm{CCT}$, pois podem predizer o grau e o estágio do tumor em função da vascularidade que este apresenta em relação ao seu tamanho. Em estudo realizado em medicina humana com 17 pacientes portadores de CCT, verificou-se que a vascularidade tumoral pode ser relacionada ao grau de invasão do tumor, embora não seja possível predizer o grau tumoral somente por essa técnica (Horstman et al., 1995).

Os objetivos desta pesquisa foram: estudar os aspectos sonográficos bidimensionais das lesões da bexiga sugestivas de CCT, analisar as dificuldades da técnica sonográfica e os possíveis diagnósticos diferenciais do CCT, investigar a contribuição da técnica de Doppler colorido no diagnóstico das lesões sugestivas de CCT e verificar a acurácia do método de biópsia ecodirigida por sucção traumática via sondagem uretral na coleta de material para a confirmação diagnóstica de CCT da bexiga.

\section{MATERIAL E MÉTODOS}

No período de outubro de 2002 a março de 2004, foram avaliados, prospectivamente, nove cães, vindos do serviço de diagnóstico por imagem.

Os critérios de inclusão dos animais foram: sinais clínicos sugestivos de neoplasia de bexiga, hematúria, polaquiúria, disúria, cistitites recorrentes ou recidivantes, associados à detecção de lesões sonográficas previamente descritas como sugestivas de CCT. Os critérios de exclusão foram: pacientes cujo acompanhamento até a obtenção do diagnóstico definitivo por meio de exames citológico/histológico, necroscópico/histológico e/ou clínico/exames-controle não tenha sido possível.

Para a ultra-sonografia, utilizou-se equipamento da marca ATL, modelo HDI $5000^{1}$, com transdutores multifreqüenciais convexos de 2 a 5 , de 4 a 7 e linear de 5 a $12 \mathrm{MHz}$. Quanto ao Doppler, o equipamento adotado compunha-se de um pulse repetition frequency (PRF), com variação de 700 a $1500 \mathrm{~Hz}$ e filtro médio a baixo. Todos os exames foram realizados por um único profissional.

$\mathrm{Na}$ interpretação das imagens ultra-sonográficas convencionais, foram determinadas a presença ou a ausência de alteração em parede vesical. Foram analisadas as características ultrasonográficas das lesões parietais: infiltrativas ou massas vegetantes, local de alteração, número e demais alterações detectadas na cavidade abdominal.

${ }^{1}$ Aparelho ATL - HDI 5000 - Philips Ultrasound - EUA. 
Quando da interpretação do Doppler colorido e/ou Doppler de amplitude no estudo da neovascularização tumoral, foram verificadas a presença ou não de sinais vasculares e o tipo de detecção dessa vascularização.

Para a confirmação do diagnóstico, foi implementada a técnica de biópsia aspirativa ecodirigida por meio de caracterização uretral. Foi realizada a sondagem uretral e, por intermédio da imagem sonográfica, visualizouse, em tempo real, o cateter uretral encostando e batendo na massa, provocando uma descamação celular. A sonda foi, então, retirada, e foram confeccionadas pelo menos 10 lâminas, coradas pela técnica Diff-Quick; tais lâminas foram analisadas ao microscópio, em aumento de 10 e 40x, para a identificação de células tumorais. Quando possível, foram realizados necropsia e exame histopatológico. Quando pertinente, também foram implementadas a urinálise e a uretrocistografia retrógrada positiva.

O diagnóstico definitivo foi confirmado pelas técnicas de punção aspirativa e/ou histopatologia, associadas à presença de lesões ultrasonográficas na bexiga.
As características sonográficas da bexiga foram comparadas ao diagnóstico final em todos os animais incluídos nesta investigação.

\section{RESULTADOS}

De acordo com os critérios de inclusão, nove cães foram selecionados. Sete desses animais apresentaram diagnóstico final de CCT, um era portador de cistite associada à hiperplasia prostática benigna (HPB), e outro estava acometido por coágulo vesical.

Os sete cães que apresentaram diagnóstico final de CCT eram fêmeas, distribuídos entre as seguintes raças: dois SRD, um Mastin Napolitano, um Husky Siberiano, um Doberman, um Lhasa Apso e um Cocker Spaniel. A faixa etária variou de nove a 13 anos (mediana igual a 10,4 anos). Dois cães com alterações vesicais benignas eram machos, sendo um Cocker Spaniel e outro Pastor Alemão, com dois e oito anos de idade, respectivamente.

A Tab. 1 traz o resumo dos achados das raças, idades, sexo, principais sinais clínicos, métodos de diagnóstico e diagnósticos definitivos dos animais com suspeita de neoplasia vesical.

Tabela 1. Descrição de raça, idade, sexo, principais sinais clínicos, achados ultra-sonográficos, métodos de diagnóstico e diagnóstico definitivo de cães com suspeita de carcinoma de células transicionais atendidos no serviço de ultra-sonografia abdominal

\begin{tabular}{|c|c|c|c|c|c|c|}
\hline Animal & Raça & $\begin{array}{l}\text { Idade } \\
\text { (anos) }\end{array}$ & Sexo & Sinal clínico & Método diagnóstico & Diagnóstico \\
\hline 1 & $\begin{array}{c}\text { Mastin } \\
\text { Napolitano }\end{array}$ & 9 & $\mathrm{~F}$ & Disúria & Biópsia ecodirigida via sondagem uretral (2x) & $\mathrm{CCT}$ \\
\hline 2 & SRD & 13 & $\mathrm{~F}$ & $\begin{array}{l}\text { Hematúria/ } \\
\text { Incontinência }\end{array}$ & $\begin{array}{l}\text { Biópsia ecodirigida via sondagem uretral( } 2 \mathrm{X})- \\
\text { não conclusiva } \\
\text { Necroscópico/histopatológico }\end{array}$ & $\mathrm{CCT}$ \\
\hline 3 & $\begin{array}{l}\text { Husky } \\
\text { Siberiano }\end{array}$ & 12 & $\mathrm{~F}$ & $\begin{array}{l}\text { Hematúria/ } \\
\text { Polaquiúria }\end{array}$ & Biópsia ecodirigida via sondagem uretral & $\mathrm{CCT}$ \\
\hline 4 & Lhasa Apso & 10 & $\mathrm{~F}$ & Hematúria & Biópsia ecodirigida via sondagem uretral & $\mathrm{CCT}$ \\
\hline 5 & Doberman & 10 & $\mathrm{~F}$ & $\begin{array}{l}\text { Disúria/ } \\
\text { hematúria }\end{array}$ & Biópsia ecodirigida via sondagem uretral & $\mathrm{CCT}$ \\
\hline 6 & $\begin{array}{l}\text { Cocker } \\
\text { Spaniel }\end{array}$ & 10 & $\mathrm{~F}$ & $\begin{array}{l}\text { Disúria/ } \\
\text { infecção urinária }\end{array}$ & Biópsia ecodirigida via sondagem uretral & $\mathrm{CCT}$ \\
\hline 7 & SRD & 9 & $\mathrm{~F}$ & Hematúria & Biópsia ecodirigida via sondagem uretral ( $2 \mathrm{x})$ & CCT \\
\hline 8 & $\begin{array}{l}\text { Cocker } \\
\text { Spaniel }\end{array}$ & 2 & M & Hematúria & $\begin{array}{l}\text { Biópsia ecodirigida via sondagem uretral } \\
\text { Exames-controle sonográficos e urinálise }\end{array}$ & Coágulos \\
\hline 9 & $\begin{array}{l}\text { Pastor } \\
\text { Alemão }\end{array}$ & 8 & M & Hematúria & Exames-controle sonográficos e urinálise & Cistite e HPB \\
\hline
\end{tabular}


No momento do exame, a vesícula urinária estava moderadamente cheia em todos os animais.

A detecção de massas exofílicas com características vegetantes foi possível em cinco cães com CCT: em dois, a massa era única e, em três, a massa apresentava características multifocais. As massas distribuíram-se da seguinte maneira: em dois animais na região do trígono (Fig. 1), em um na região do trígono, protraindo-se para o ureter, em um na parede ventral, e em três com localização multifocal (Fig. 2). Os tumores apresentaram ecogenicidade complexa: ecogênica tendendo a hiperecóica, algumas com áreas de microcalcificação em seu interior. As massas apresentavam contorno irregular e com progressão para o lúmen vesical, e havia sempre transição abrupta entre a parede normal e a região do tumor.

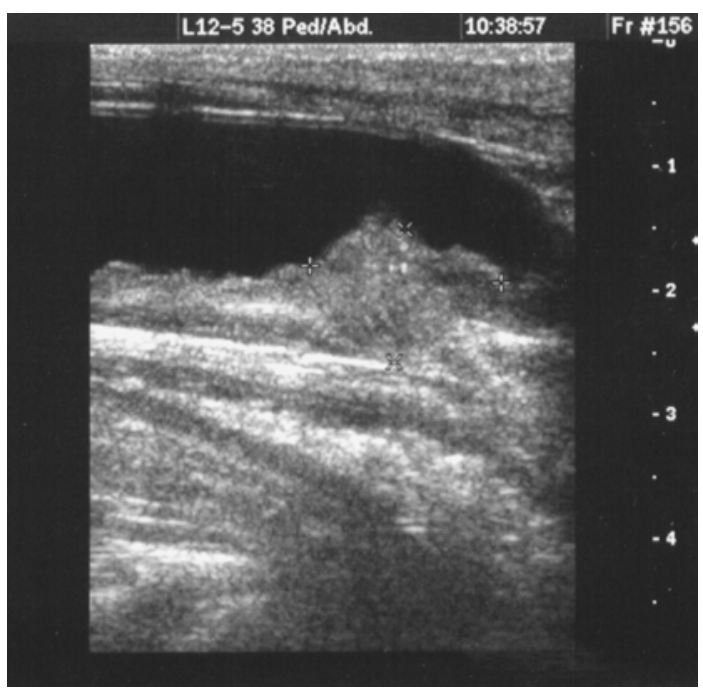

Figura 1. Imagem ultra-sonográfica de cão demonstrando espessamento parietal focal, irregular, com aspecto de massa exofílica, localizado na região de trígono vesical.

Em dois casos de CCT, a característica sonográfica visualizada foi de lesão infiltrativa da parede: um apresentava lesão somente dorsal, e o outro tinha lesão dorsal e ventral. Em um dos casos foram também observados pontos de microcalcificações aderidos à superfície da porção alterada da parede. Nos dois cães, a lesão encontrava-se na região do colo vesical, progredindo para a uretra proximal. Em um dos animais, além do exame sonográfico, foi necessária a realização da uretrocistografia retrógrada positiva para confirmar o diagnóstico e apurar a avaliação da extensão da lesão na uretra.

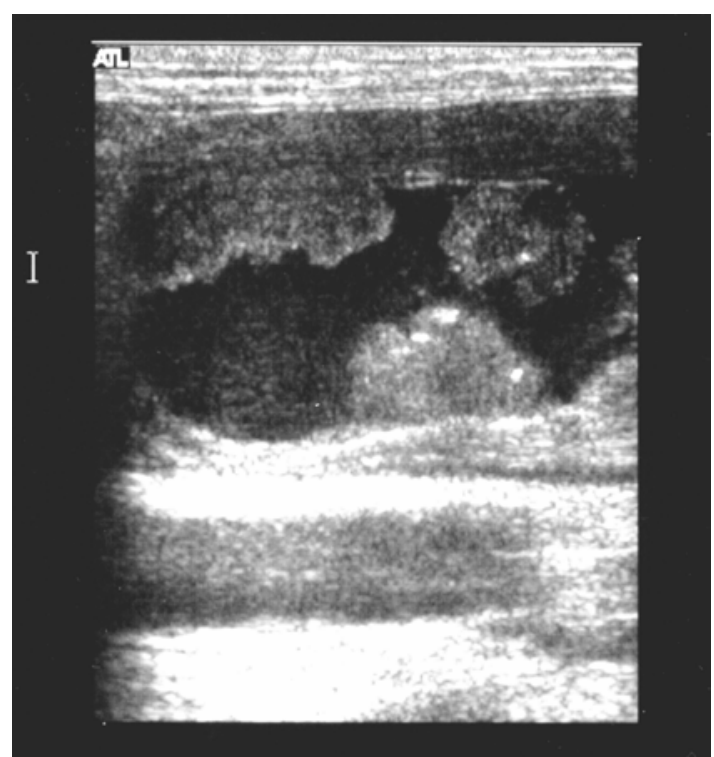

Figura 2. Imagem ultra-sonográfica de cão demonstrando massas multifocais, irregulares, vegetantes, hiperecóicas e com microcalcificações a partir da superfície interna na parede da bexiga.

Dos sete animais com CCT, seis apresentavam outras alterações detectadas na cavidade abdominal sendo: um com nódulo hepático, um com linfonodomegalia ilíaca, dois com aumento de ecogenicidade de córtex renal, um com dilatação pélvica discreta, dois com hidronefrose e megaureter, um com invasão da massa em ureter distal e três com esplenomegalia com parênquima levemente heterogêneo.

Nos dois casos em que o diagnóstico de CCT foi excluído, as alterações ultra-sonográficas visualizadas foram: espessamento difuso e grave da parede vesical com aumento subjetivo da próstata, associado a microcistos entremeados no parênquima, sendo confirmada cistite inflamatório-infecciosa, e HPB por meio de exames laboratoriais e controles sonográficos, 30 dias após a orquiectomia.

No cão com diagnóstico de coágulo vesical, a ultra-sonografia possibilitou a constatação de massa irregular ecogênica tendendo a hipoecóica, na região intraluminal vesical, aparentemente 
aderida na parede da bexiga e sem vascularização no Doppler colorido. Mesmo após a técnica de balotamento e lavagem via sondagem uretral, não houve alteração do aspecto da massa. Assim, o paciente foi submetido à citologia aspirativa por sucção traumática via sondagem uretral, e não foram detectadas alterações sugestivas de neoplasia vesical. Após o resultado dos exames laboratorias, foi constatada anemia regenerativa auto-imune, e o exame-controle sonográfico, realizado 48 horas após o ínicio da terapia, demonstrou que a bexiga encontrava-se sem alterações.

Em quatro animais portadores de CCT, o exame realizado com Doppler colorido e Doppler de amplitude possibilitou a observação de vascularização interna na massa por meio de fluxo sangüíneo central, e conjuntamente central mais periférico (Fig. 3). Não foi visualizada a presença de vascularização interna na lesão confirmada como coágulo vesical, também avaliada.

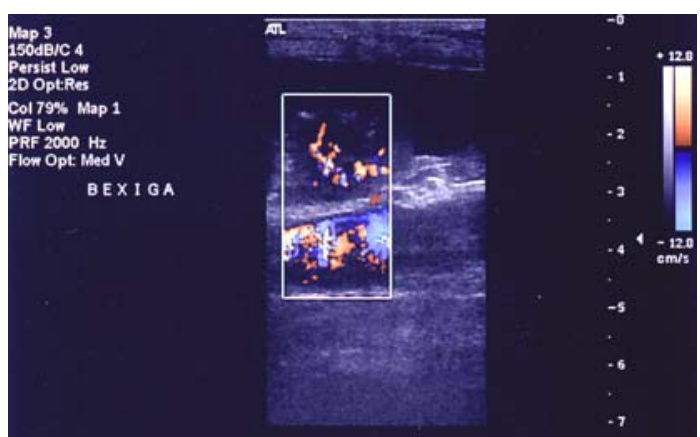

Figura 3. Imagem do mapeamento Doppler colorido de cão demonstrando presença de fluxo sangüíneo - hipervascularização na massa vesical. Neoangiogênese tumoral.

A técnica de sucção traumática por aspiração possibilitou o diagnóstico em cinco dos sete animais com CCT. Em um desses pacientes, foi necessário realizar o procedimento mais de uma vez (Fig. 4). Em um dos casos, não foi possível a elucidação diagnóstica, porque a quantidade de material adquirido era escassa. Esse animal tinha lesão infiltrativa na parede e não apresentava massa vegetante.

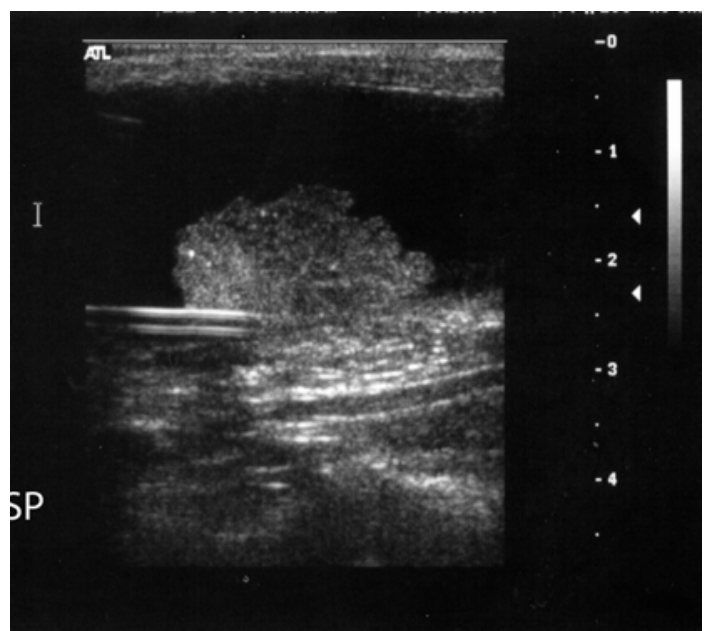

Figura 4. Imagem ultra-sonográfica de cão demonstrando massa irregular e ecogênica aderida à parede e sonda uretral tocando na mesma.

\section{DISCUSSÃO}

$\mathrm{Na}$ medicina veterinária, muitas vezes, o diagnóstico dos tumores vesicais é realizado tardiamente, pois os animais com hematúria e disúria são tratados, previamente, para cistites inflamatório-infecciosas. Assim, o médico veterinário deve solicitar exames de diagnóstico por imagem, principalmente quando se defrontar com pacientes portadores de cistites recidivantes e intermitentes, ou que apresentem características etiológicas e clínicas sugestivas para o CCT (Phillips, 1999; Henry, 2003).

Atualmente, o exame ultra-sonográfico é o procedimento de diagnóstico por imagem mais indicado em tais casos por ser um método simples, que facilmente permite a identificação do órgão devido à sua posição superficial e ao seu preenchimento com conteúdo líquido. Normalmente se visualiza uma estrutura anecóica circundada por uma estrutura ecogênica fina, a parede. A mucosa e a musculatura da parede não são identificadas separadamente quando normais (Lévillé et al., 1992; Nyland et al., 2002; Park e Wrigley, 2003).

Assim, fatores técnicos podem influenciar na observação das alterações, principalmente quando se buscam lesões sugestivas de tumores vesicais, e um desses fatores é o grau de repleção vesical. É importante que a vesícula urinária esteja moderadamente cheia quando de sua 
avaliação, evitando perda de alterações na parede ou imagens falso-positivas de espessamentos. Para tanto, caso o animal, no momento do exame, não esteja com a repleção vesical adequada, é aconselhável esperar entre 30 minutos e uma hora, ou repetir o exame no outro dia, no período da manhã, momento em que normalmente o órgão encontra-se repleto, aspecto mencionado por Lévillé et al. (1992).

Com relação às características clínicas e de idade dos animais avaliados na presente pesquisa, verificou-se que tais achados estão em consonância com a literatura consultada, que aponta a prevalência de CCT em cadelas idosas (Caywood et al., 2003; Henry, 2003).

A detecção e o aspecto ultra-sonográfico das massas exofílicas, suas características de ecogenicidade, de forma, de contorno e de posicionamento observados nesta investigação foram semelhantes àqueles relatados por Lévillé et al. (1992), Park e Wrigley (2003) e Gianini e Cerri (2002). Isto significa que lesões do CCT com esse aspecto sonográfico são facilmente detectadas, ao contrário daquelas de aspecto infiltrativo, observadas em dois casos, que ocasionalmente mostram um pequeno componente intraluminal, difíceis de se identificar, principalmente devido à sua localização topográfica, na região de colo vesical e uretra proximal. É importante lembrar que, para excluir achados sonográficos compatíveis com massas vegetantes em cadelas suspeita de CCT e com sinais clínicos de disúria, indica-se a realização de uretrocistografia retrógrada positiva, em razão da dificuldade de localizar as alterações no colo vesical e uretra proximal.

As microcalcificações, ocasionalmente vistas na superfície do tumor, são, provavelmente, secundárias à infecção, como citaram Gianini e Cerri (2002).

Lévillé et al. (1992) mencionaram que o tamanho do tumor é um importante fator para detectá-lo. Todas as massas exofílicas constatadas no presente estudo tinham tamanho superior a $0,5 \mathrm{~cm}$ e, provavelmente por isso, foram facilmente identificadas. Contudo, mais uma vez, é importante salientar os diagnósticos falsopositivos, decorrentes da pouca repleção vesical ou de outras alterações, como cistites polipóides, alterações pós-operatórias e outros tumores primários ou metastáticos. Em casos dessa ordem, a cistoscopia e a biópsia são necessárias para a elucidação diagnóstica.

Os coágulos também podem ser confundidos com as massas vesicais (Lévillé et al., 1992; Park e Wrigley, 2003). Em um dos animais desta investigação, a presença de massa vesical hipoecóica, irregular e aparentemente aderida à parede foi inicialmente confundida com CCT. Nesse caso, a técnica de balotamento sugerida por Finn-Bodner (1995) não ajudou na diferenciação diagnóstica, ao contrário da técnica de Doppler colorido e Doppler de amplitude que, após a análise, confirmou a ausência de sinais de vascularização, indicando tratar-se de um coágulo confirmado por exame citológico e controle sonográfico em 48 horas.

Nos outros quatro animais com massas vegetantes avaliados pelas técnicas de Doppler colorido e Doppler de amplitude, verificaram-se sinais de hipervascularização, indicativos de neoangiogênese tumoral, aparentemente confirmando ainda mais a suspeita de neoplasia vesical e indicando a alta invasibilidade da tumoração na parede vesical.

As outras alterações detectadas na ultrasonografia bidimensional da cavidade abdominal nos seis cães portadores de CCT foram provenientes da invasão tumoral desses locais e também da proximidade do tumor a essas estruturas, o que provocou indícios de processos obstrutivos do trato urinário, facilmente detectados pelo exame.

Em um animal foi visualizada a presença de nódulo hepático, e em outro foi possível identificar a linfonodomegalia ilíaca, sítios mais comuns de metástases mencionados na medicina humana.

A esplenomegalia, com o parênquima levemente heterogêneo, foi observada em alguns animais com CCT, achado que não consta da literatura pesquisada. Uma das hipóteses sugeridas para a presença dessa alteração seria as metástases infiltrativas no parênquima. Entretanto, como tais animais não foram submetidos a exame histopatológico, permanece a dúvida sobre essa alteração. 
A técnica de sucção traumática por aspiração permitiu o diagnóstico em cinco dos sete animais portadores de CCT, todos eles com lesão vegetante. Nenhum animal manifestou complicação após o procedimento, o que confirma que essa é uma técnica simples e de baixo risco; a única recomendação para utilizála, de acordo com Lamb et al. (1996), é que a bexiga deva ser parcialmente esvaziada.

Nos casos em que a lesão era infiltrativa, a técnica de sucção traumática não foi eficiente e, conseqüentemente, não foi possível coletar o material. Em pacientes com esse quadro, outros procedimentos diagnósticos, como a cistoscopia, são indicados.

\section{CONCLUSÕES}

A ultra-sonografia é um importante método de avaliação de animais com suspeita de CCT, pois identifica alterações características dessa afecção. A grande dificuldade de detecção ultrasonográfica da $\mathrm{CCT}$ está relacionada às lesões infiltrativas, que invadem o colo vesical e a uretra proximal. As técnicas de Doppler colorido e Doppler de amplitude demonstram a hipervascularização, que detecta a neoangiogênese tumoral e auxilia na confirmação de tumores vesicais, principalmente na diferenciação dos coágulos aderidos na parede. A punção aspirativa por sucção traumática é um procedimento aparentemente indolor, simples e com poucos riscos de complicação, permitindo uma boa acurácia na aquisição de células neoplásicas nos casos de massas vegetantes vesicais. A ultra-sonografia é a primeira técnica de diagnóstico por imagem indicada para pacientes que apresentem hematúria e disúria.

\section{REFERÊNCIAS BIBLIOGRÁFICAS}

CAYWOOD, D.D.; KLAUSNER, J.S.; WALTERS, P.A. Sistema urinário. In: SLATTER. D.H. Textbook of small animal surgery. 2.ed. Philadelphia: W.B. Saunders, 2003. p.2593-2605.
FINN-BODNER, S.T. The urinary bladder. In: CARTEE, R.E.; SELCER,B.A.; HUDSON, J.A. et al. Practical veterinary ultrasound. Philadelphia: Lea \& Fiberger, 1995. p.220-235.

GIANINI, F.R.G.S.; CERRI, L.M.O. Bexiga e uretra. In: CERRI, G.G.; OLIVEIRA, I.R.S. Ultra-sonografia abdominal. Rio de Janeiro: Revinter, 2002. p.493-521.

HENRY, J.C.; TYLER, J.W.; McENTEE, M.C. et al. Evaluation of a bladder tumor antigen test as a screening tes for transitional cell carcinoma of the lower urinary tract in dogs. Am. J. Vet. Res., v.40, p.1017-1020, 2003.

HENRY,C.J. Management of transitional cell carcinoma. Vet. Clin. Small Anim., v.33, p.597613, 2003.

HORSTMAN, W.G.; McFARLAND,R.M.; GORMAN, J.D. Color Doppler sonography findings in patients with transitional cell carcinoma of the bladder and renal pelvis. $J$ Ultrasound Med., v.14, p.129-133, 1995.

LAMB, C.R.; TROWER, N.D.; GREGORY, S.P. Ultrasound guided catheter biopsy of the lower urinary tract: technique and results in 12 dogs. J. Small Anim. Pract., v.37, p.413-416, 1996.

LÉVEILLÉ, R.; BILLER, D.S.; PARTINGTON, B.P. et al. Sonography investigation of transitional cell carcinoma of the urinary bladder in small animals. Vet. Radiol. Ultrasound, v.33, p.103-107, 1992.

NYLAND, T.G.; MATTOON, J.S.; HERRGESELL,E.J. et al. In: NYLAND, T.G.; MATTOON, J.S. Small animal diagnostic ultrasound. 2.ed. Philadelphia: WB Saunders, 2002. p.158-195.

PARK, R.D.; WRIGLEY, R.H. The urinary bladder. In: THRALL, D.E. Textbook of veterinary diagnostic radiology. 4.ed. Philadelphia: W.B. Saunders, 2003.

PHILLIPS, B.S. Bladder tumors in dogs and cats. Compend. Contin. Educ. Pract. Vet., v.21, p.540-547, 1999. 